\title{
The Rainfall Annual Cycle Bias over East Africa in CMIP5 Coupled Climate Models
}

\author{
WENCHANG YANG \\ Department of Earth System Science, University of California, Irvine, Irvine, California \\ Richard SEAGER AND MARK A. CANE \\ Lamont-Doherty Earth Observatory, Columbia University, Palisades, New York \\ BRADFIELD LYON \\ International Research Institute for Climate and Society, The Earth Institute, and Lamont-Doherty Earth \\ Observatory, Columbia University, Palisades, New York
}

(Manuscript received 1 May 2015, in final form 27 August 2015)

\begin{abstract}
East Africa has two rainy seasons: the long rains [March-May (MAM)] and the short rains [OctoberDecember (OND)]. Most CMIP3/5 coupled models overestimate the short rains while underestimating the long rains. In this study, the East African rainfall bias is investigated by comparing the coupled historical simulations from CMIP5 to the corresponding SST-forced AMIP simulations. Much of the investigation is focused on the MRI-CGCM3 model, which successfully reproduces the observed rainfall annual cycle in East Africa in the AMIP experiment but its coupled historical simulation has a similar but stronger bias as the coupled multimodel mean. The historical-AMIP monthly climatology rainfall bias in East Africa can be explained by the bias in the convective instability $(\mathrm{CI})$, which is dominated by the near-surface moisture static energy (MSE) and ultimately by the MSE's moisture component. The near-surface MSE bias is modulated by the sea surface temperature (SST) over the western Indian Ocean. The warm SST bias in OND can be explained by both insufficient ocean dynamical cooling and latent flux, while the insufficient shortwave radiation and excess latent heat flux mainly contribute to the cool SST bias in MAM.
\end{abstract}

\section{Introduction}

East Africa has been undergoing increased frequency and intensity of droughts in recent decades, raising the question of whether the drying trend will continue in a warmer future climate as forced by anthropogenic emissions of greenhouse gases (GHGs). Some studies proposed that the recent drying trend can be attributed to SST anomalies over the Indian Ocean induced by anthropogenic forcing (Funk et al. 2008; Williams and Funk 2011), suggesting an extension of the current drying trend into the near future. However, there is a strong consensus in model projections from the Intergovernmental Panel on Climate Change (IPCC)

Corresponding author address: Wenchang Yang, 2101F Croul Hall, Irvine, CA 92697.

E-mail: yang.wenchang@uci.edu
Fourth Assessment Report (AR4) and the more recent phase 5 of the Coupled Model Intercomparison Project (CMIP5; Taylor et al. 2012) that precipitation over East Africa will increase (Shongwe et al. 2011; Otieno and Anyah 2013a,b), implying that the current dry conditions will be, at least partly, ameliorated in the near future.

The reliability of these optimistic projections on East African future hydroclimate and their suitability to serve as the foundation for the development community, however, depend on the performance of the models in reproducing past and current East African hydroclimate. By examining the performance of both SSTforced (AMIP style) models and the coupled models used in the CMIP5 historical experiment (CMIP style) in simulating the East African long rains [March-May (MAM)], Yang et al. (2014) showed that the SST-forced models are in general able to capture the observed 
decadal variability of the long rains, which is primarily driven by the SST variations over the Pacific Ocean. The coupled models, which are used for the twenty-first century climate projections, however, generally fail to capture the correct long rains-SST relationship on decadal or longer time scales. Moreover, the coupled models misrepresent the East African rainfall annual cycle by overestimating the short rains [OctoberDecember (OND)] and underestimating the long rains, which has also been reported for the CMIP3 coupled models (Anyah and Qiu 2012). The cause of the rainfall annual cycle bias in the CMIP5 coupled models and its implications for the projections from these coupled models are still not clear.

Previous studies have revealed that there are some global- or tropical-scale biases in the coupled models of CMIP3 and CMIP5, e.g., the excessive equatorial Pacific cold tongue and double intertropical convergence zone (ITCZ) ( $\mathrm{Li}$ and Xie 2014), weak Atlantic meridional overturning circulation (AMOC) (Wang et al. 2014), and an unrealistic mean thermocline slope tilting upward toward the eastern Indian Ocean (Cai and Cowan 2013; Li et al. 2015). These large-scale biases in the coupled models might potentially affect the precipitation simulations over East Africa and the linkage between the two needs to be explored. In explaining the East African rainfall annual cycle, Yang et al. (2015) proposed that it is modulated by the near-surface moist static energy (MSE), which in turn is controlled by the off-coast SSTs as well as the low-level atmospheric circulation. Here we examine whether the MSE framework can be applied to understand the annual cycle bias over East Africa in the CMIP5 coupled models.

In this paper, we will analyze the coupled-modelinduced bias of the East African rainfall annual cycle by comparing the historical and AMIP simulations for each model, with particular emphasis on the MRI-CGCM3 model, which best simulates the East African rainfall annual cycle in the AMIP run but has a coupled model bias typical of the multimodel mean. The paper is organized as follows: section 2 describes the data and models used in this study as well as some special treatment of calculations, section 3 shows the historicalAMIP bias from multimodel statistics and individual models, detailed analysis of the MRI-CGCM3 is in section 4 , and the main conclusions of the paper and associated discussion are provided in section 5 .

\section{Data, models, and methods}

For observed precipitation, we use version 6 of the Global Precipitation Climatology Centre (GPCC) monthly precipitation (Rudolf et al. 2010), which is a gauge-based, $0.5^{\circ}$ longitude $\times 0.5^{\circ}$ latitude gridded global land surface dataset for the period of 1901-2010; version TS 3.21 of monthly precipitation over global land areas from the Climatic Research Unit at the University of East Anglia (CRU; Harris et al. 2014) covering from 1901 to 2009; version 2.2 of the Global Precipitation Climatology Project (GPCP) monthly precipitation dataset from 1979 to 2010 (Huffman et al. 2009), which combines gauge observations and satellite data into $2.5^{\circ} \times 2.5^{\circ}$ global grids; Climate Prediction Center (CPC) Merged Analysis of Precipitation (CMAP) (Xie and Arkin 1997), which is also monthly satellite and gauge data covering from 1979 to 2011; version 7 of Tropical Rainfall Measuring Mission (TRMM) daily precipitation (Huffman et al. 2007) covering from 1998 to 2014; and precipitation from the European Centre for Medium-Range Weather Forecasts (ECMWF) interim reanalysis (ERA-Interim) (Dee et al. 2011), which covers the post-1979 period and is the latest of the ECMWF reanalyses.

In this study, 21 of the CMIP5 models that have precipitation available for both the historical and AMIP experiments are used. (Their names are listed in Fig. 3 and Fig. 4.) Only one run is chosen from each model in the calculation of the multimodel mean and other statistics across these models. As most models cover only the period before 2005 for the historical runs, the base period we choose to calculate climatology for both observations and simulations is 1979-2005 except that for the TRMM daily precipitation data, where $1998-2005$ is used instead. In this study, we focus on the land areas of East Africa $\left(10^{\circ} \mathrm{S}-12^{\circ} \mathrm{N}, 30^{\circ}-52^{\circ} \mathrm{E}\right)$ that show a bimodal rainfall annual cycle and an arid/semiarid annual mean climatology by applying the following criteria to the GPCC precipitation dataset: 1) precipitation rate in March-May greater than both seasons of JanuaryFebruary and June-September and 2) annual mean precipitation rate less than $2 \mathrm{~mm} \mathrm{day}^{-1}$. The first criterion follows Yang et al. (2015) to exclude the monsoonal areas with a single rainfall peak in local summer and thus isolates the bimodal annual cycle region. The second criterion is added here to exclude the active equatorial convection areas where there are also two rainy seasons but the annual mean rainfall is much larger than in the arid/semiarid areas. The resulting areas over East Africa are shown as gray grids in the mini panel of Fig. 1. Area average over East Africa in this study is only applied to these grids unless otherwise stated.

\section{CMIP5 multimodel statistics}

Figure 1 shows the East African rainfall annual cycles from different observational datasets: ERA-Interim 


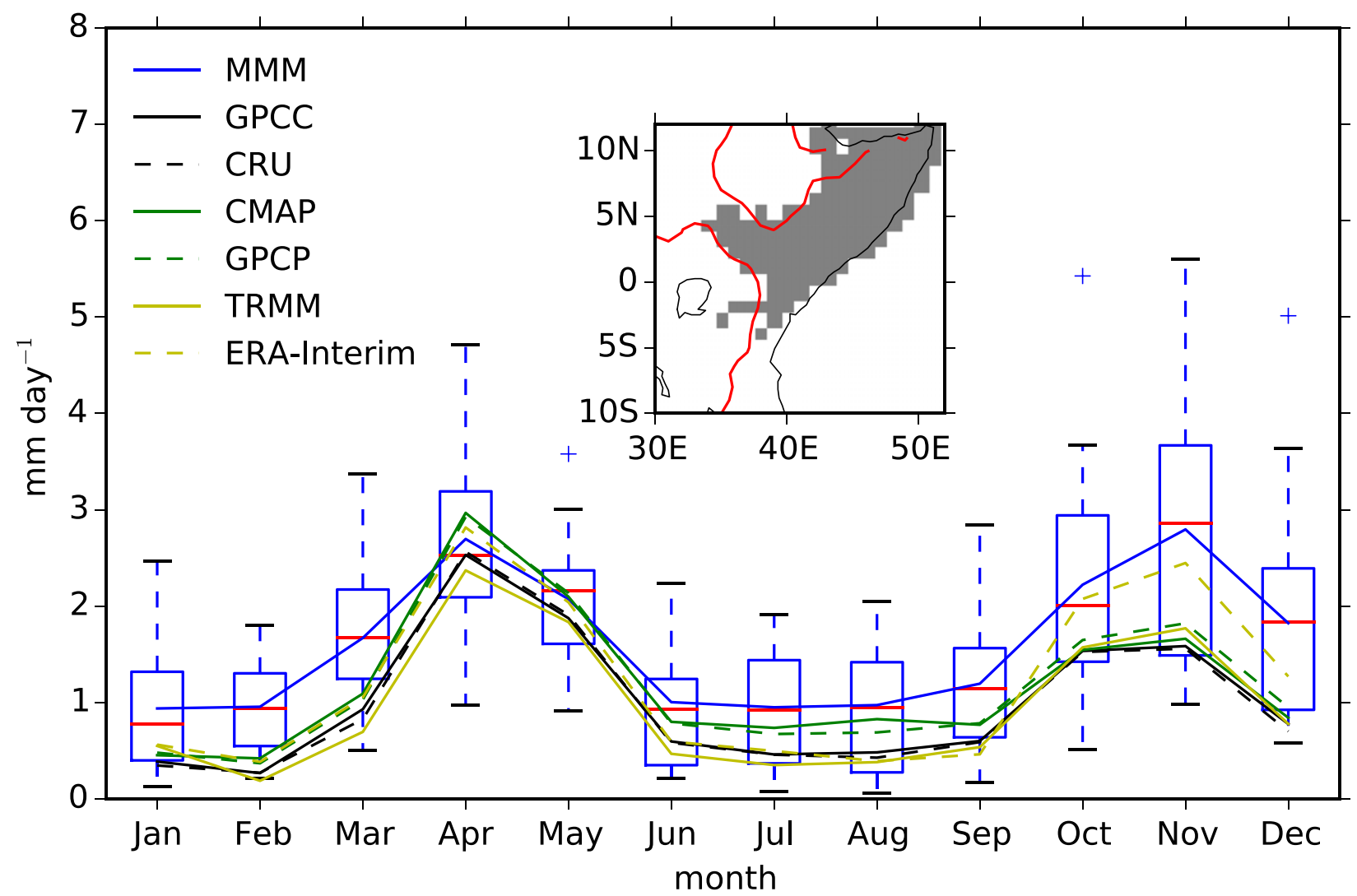

FIG. 1. East African rainfall annual cycles from observations, ERA-Interim, and AMIP runs of 21 CMIP5 models. All of the annual cycles are averaged over the gray shaded grids as shown in the mini panel, where the red lines are the 1-km elevation contours. Box plots show the statistics across the 21 models and the blue line is the multimodel mean (MMM).

and AMIP runs of the 21 CMIP5 models. The observed annual cycles are close to each other, whether the observation is based on gauge (GPCC and CRU) or satellite (TRMM) or their combination (CMAP and GPCP), establishing a solid reliability for the observed rainfall annual cycle over East Africa. The characteristic bimodal annual cycle is apparent from the observations, with the major rainy season during MAM (long rains) and the second rainy season during OND (short rains). Precipitation from ERA-Interim generally follows the observed annual cycle except for the short rains where the reanalysis can be $0.5 \mathrm{~mm} \mathrm{day}^{-1}$ greater than the observed. Because a reanalysis dataset is influenced both by the assimilated observations and by the model, reanalyses may share some similar biases with GCMs especially for precipitation. Rainfall annual cycles from the AMIP runs show some degree of spread among different models but the multimodel mean (the blue line) or their median (red horizontal lines in the boxes) does reproduce the bimodal feature. However, the multimodel mean overestimates the rainfall in all months except April and May. The short rains are positively biased in models such that they are comparable with the long rains. This bias in AMIP runs might arise from the AGCM's excess precipitation response to the SST gradient over the western Indian Ocean as found in previous work (e.g., Bollasina and Ming 2013) and will not be addressed here. Instead, we will focus on the bias arising from the atmosphereocean coupling by comparing CMIP5 historical runs to the AMIP runs.

Figure 2 shows the difference of East African rainfall annual cycles between the historical coupled runs and the corresponding AMIP runs from the 21 CMIP5 models. The historical-AMIP rainfall differences are largely negative from January to May. Moreover, the historical run is drier than the AMIP for all models during February-April, with the largest multimodel mean discrepancy $\left(>1 \mathrm{~mm} \mathrm{day}^{-1}\right)$ occurring in April. During the summer season of June-September (JJAS), the historical-AMIP rainfall difference is near zero and only the September multimodel mean difference is greater than $0.5 \mathrm{~mm}$ day $^{-1}$. The multimodel mean difference of historical-AMIP rainfalls peaks at around 


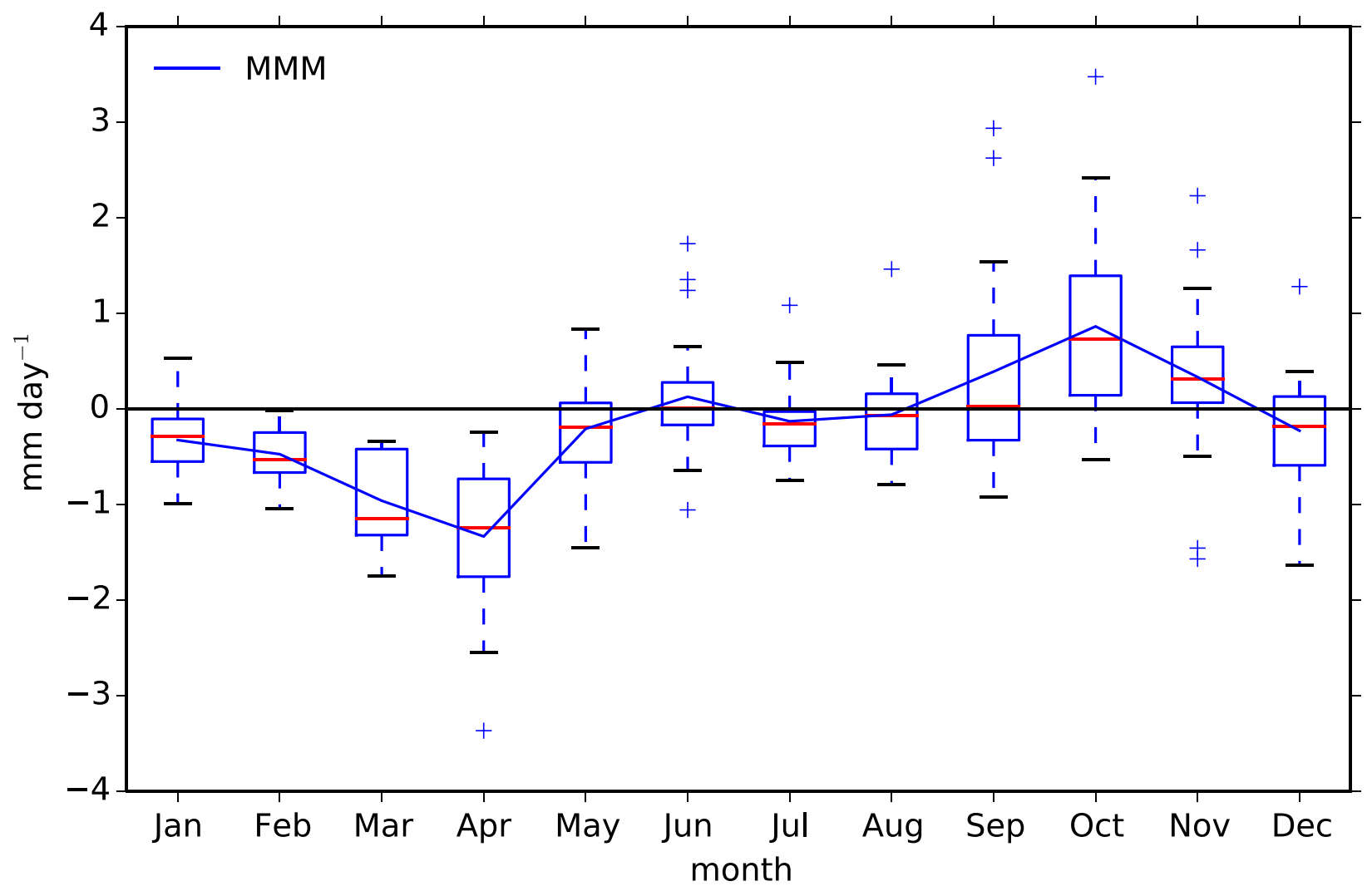

FIG. 2. East African historical-AMIP rainfall annual cycles from 21 models of CMIP5 (box plots). The blue line is the MMM, which is significant from zero at the level 0.1 of the two-sided Student's $t$ test for months January, February, March, April, and October.

$1 \mathrm{~mm} \mathrm{day}^{-1}$ in October, the first month of the short rains, decreases during the following two months, and falls to a slight negative value in December. Overall, the historical runs are wetter than the AMIP runs during the short rains and drier during the long rains.

Figure 3 shows the East African rainfall annual cycles of CMIP5 individual models for the AMIP and historical runs as compared to the GPCC result. For most models, the historical runs (red lines) are wetter than the AMIP runs (blue lines) during OND while they are drier during MAM especially April, consistent to the multimodel mean historical-AMIP results in Fig. 2. For the AMIP run, some models are highly correlated with the GPCC (e.g., MRI-CGCM3, IPSLCM5A-LR, FGOALS-g2, and CSIRO Mk3.6.0) while some models are not [e.g., Institute of Numerical Methods of the Russian Academy of Sciences, Climate Model, version 4 (INMCM4), BNU-ESM, and NorESM1-M]. The correlation coefficients with the GPCC, as well as the root-mean-square errors (RMSE) compared to the GPCC, for all the CMIP5 AMIP and historical runs are shown in the scatterplots of Figs. $4 \mathrm{a}$ and $4 \mathrm{~b}$. There are five AMIP models with a correlation coefficient greater than 0.8 and a RMSE less than $0.5 \mathrm{~mm} \mathrm{day}^{-1}$, namely MRI-CGCM3, IPSL-CM5A-LR, IPSL-CM5A-MR, CMCC-CM, and MPI-ESM-MR (Fig. 4a). Moving from AMIP to historical runs (Fig. 4b), all of them have a higher RMSE and four of them (except MPI-ESM-MR) have a less correlation coefficient. Of all these 21 models, MRI-CGCM3 is of particular interest. Its AMIP run reproduces the GPCC annual cycle very well but when coupled, it dramatically overestimates the OND rainfall and underestimates the MAM rainfall, similar to the coupled multimodel mean bias. Therefore, MRI-CGCM3 serves as an ideal model to study the bias induced by turning from SST-forced GCMs into atmosphereocean coupled GCMs.

\section{Results from MRI-CGCM3}

Figure 5 shows the historical-AMIP monthly climatology rainfall difference of MRI-CGCM3 over East Africa and surrounding areas. It is largely negative over East Africa from January to May and the absolute value is greatest in April, consistent with the 


\section{EA rainfall annual cycle in obs and CMIP5 models}
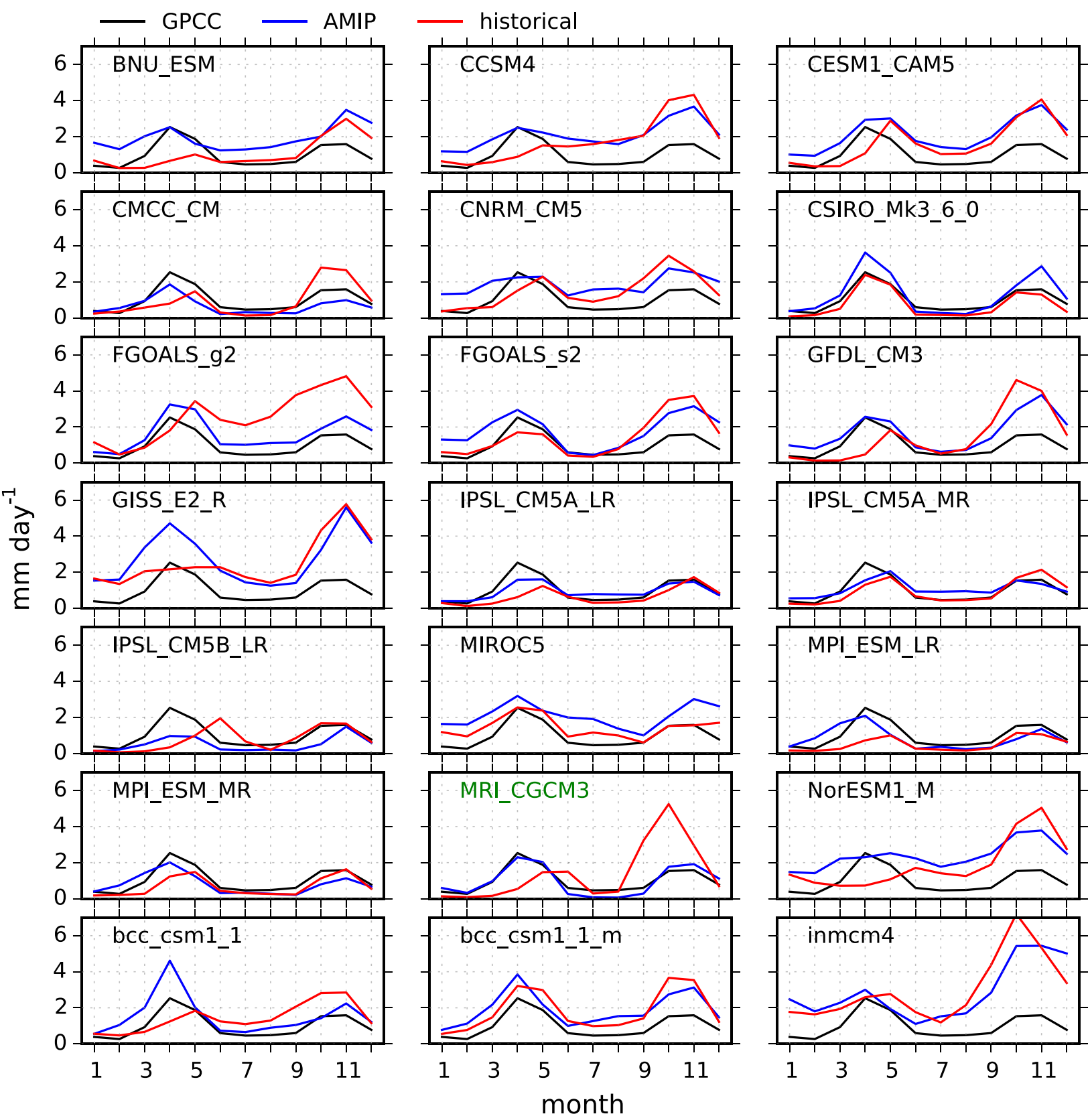

FIG. 3. East African rainfall annual cycles in GPCC and CMIP5 individual models for the AMIP and historical experiments.

multimodel mean result in Fig. 2. It is noted that the January-May negative values over East Africa are accompanied by a large-scale pattern of dry north and wet south over the Indian Ocean, suggesting that the dry biases might be associated with large-scale dynamics and the associated southward shifts of the ITCZ in the historical runs. Starting from June, a strong wet bias develops over the western Indian Ocean, abruptly shifting the biases over the Indian Ocean into a new pattern of wet west and dry east and keeping this new pattern until the end of the year. This large-scale shift of the historical-AMIP precipitation difference has important impacts over East Africa, turning the previous negative precipitation biases into positive from June to November. The positive bias over East Africa peaks in September and October and turn slightly 

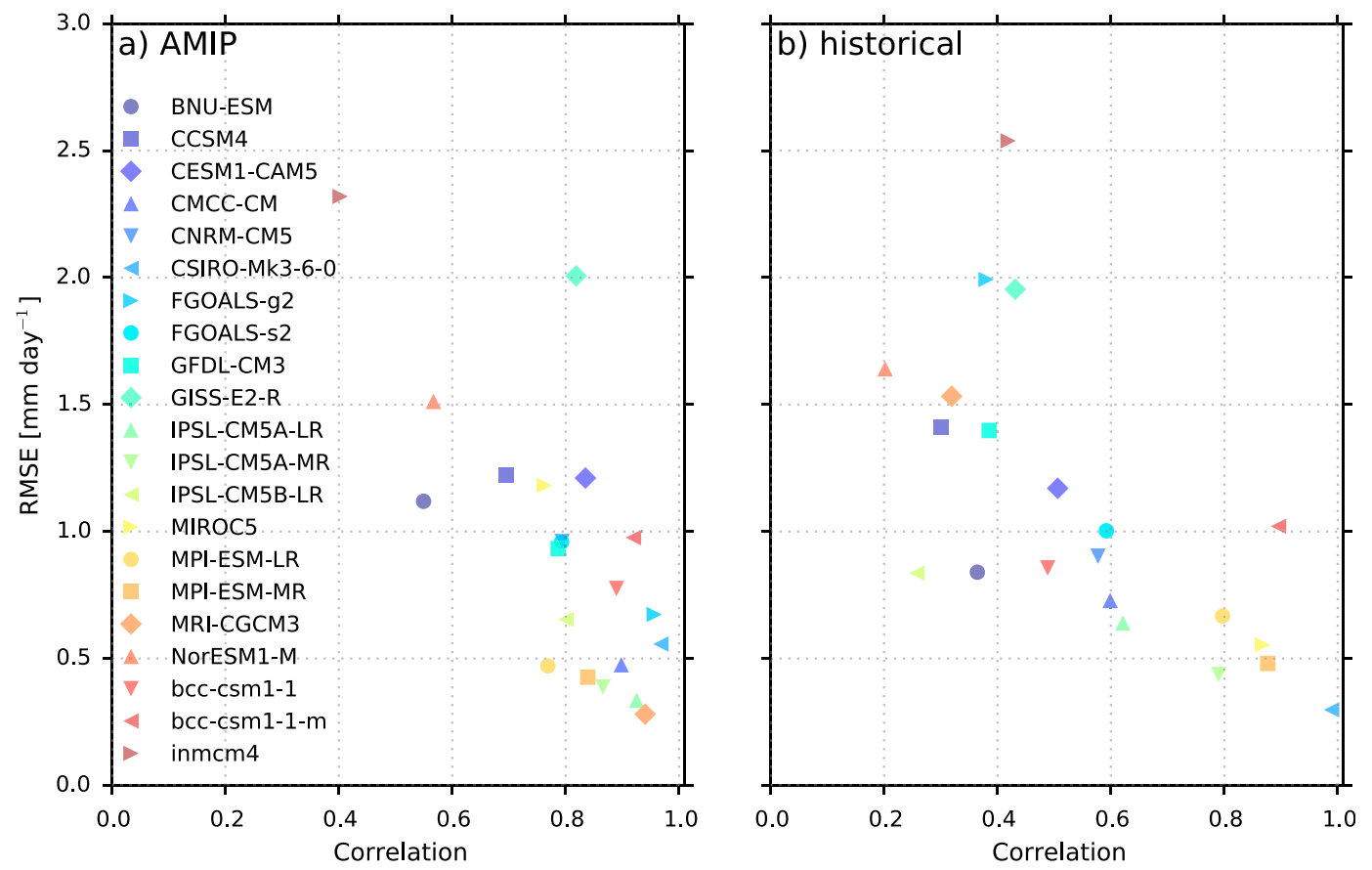

FIG. 4. Scatterplot of correlation coefficient with the GPCC rainfall annual cycle vs RMSE compared to the GPCC for the CMIP5 (a) AMIP and (b) historical runs.

negative in December, consistent with the multimodel mean result in Fig. 2.

\section{a. Convective instability and MSE}

To understand the historical-AMIP monthly climatology rainfall difference in MRI-CGCM3, we calculate the convective instability (CI) as measured by near-surface moist static energy minus $700-\mathrm{hPa}$ saturated moist static energy (Yang et al. 2015). The historical-AMIP monthly climatology of the CIs are shown in Fig. 6. The CI differences generally agree well with rainfall in Fig. 5. There is also a large-scale north-south contrast from January to May over the Indian Ocean. During this period, the northern Indian Ocean and East Africa have negative CI differences, implying that the atmosphere over these regions is more stable and precipitation is suppressed in the historical run compared to in the AMIP run, which explains the dry bias over these regions in Fig. 5. The CI also develops a positive bias over the western Indian Ocean starting from June, destabilizing the atmosphere in the historical run and enhancing precipitation there and over East Africa. It should be noted that the evolutions of the $\mathrm{CI}$ and rainfall biases are not synchronous over East Africa after June and the CI seems to lead rainfall by one month. For example, the CI bias over East Africa peaks in August and September while the rainfall bias peaks in September and
October. Also, the CI bias turns negative over much of East Africa in November while the rainfall bias is still slightly positive and becomes negative in December.

We decompose the CI into its components of nearsurface moist static energy and 700-hPa saturated moist static energy and find the former is the dominant term and the latter is secondary and has a slightly destabilizing effect over East Africa. Therefore, the dominant component of the near-surface moist static energy is further decomposed into components associated with near-surface temperature, moisture, and geopotential and it is found that the temperature and geopotential components are much smaller in magnitude than the moisture component, which is shown in Fig. 7. It has very similar spatial patterns to those of CI in Fig. 6. Hence the change in $\mathrm{CI}$ is dominated by the change in low-level specific humidity, which is also the case for the CI annual cycle in observations (Yang et al. 2015).

Figure 8 summarizes the relationship between rainfall biases of historical-AMIP and CI as well as its different components for MRI-CGCM3. The rainfall bias annual cycle (black solid line) is very similar to the multimodel mean (blue solid line in Fig. 2) and characterized by overall positive values in the short rains but negative values in the long rains. The rainfall bias can be explained by the CI bias and the latter in general leads by one month. Decomposition of the CI shows that the 
historical-AMIP rainfall in MRI-CGCM3
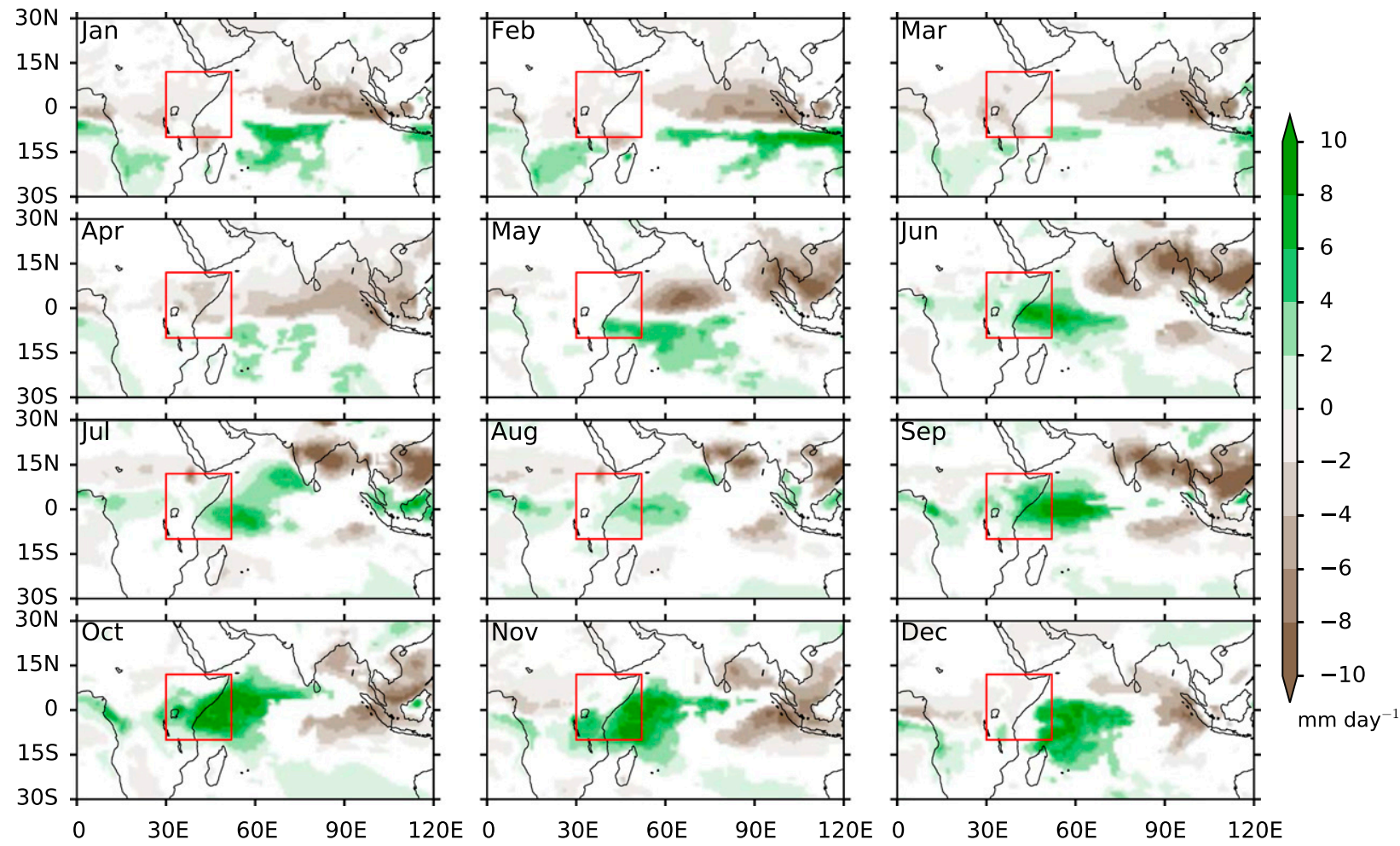

FIG. 5. Historical-AMIP monthly climatology rainfall in MRI-CGCM3. The red box outlines the region of $10^{\circ} \mathrm{S}-12^{\circ} \mathrm{N}, 30^{\circ}-52^{\circ} \mathrm{E}$. Only grids significant at the level 0.05 of the two-sided Student's $t$ test are shaded.

moisture component of the near-surface moist static energy emerges as the dominant component.

\section{b. Surface temperature and heat flux}

The fact that the historical-AMIP CI bias, or equivalently the near-surface moist static energy bias, agrees well with the rainfall bias raises the question of what controls the near-surface moist static energy anomaly. Yang et al. (2015) proposed that SSTs over the western Indian Ocean play an important role in modulating the East African rainfall annual cycle via controlling the near-surface moist static energy of the air flowing onto the continent. We therefore examine if this mechanism can be applied to explain the rainfall difference between the historical run and the AMIP run. Figure 9 shows the historical-AMIP monthly climatology surface temperature (which is SST over the ocean) for the MRI-CGCM3. This is very similar to the spatial patterns of CI in Fig. 6 or the moisture component of near-surface moist static energy in Fig. 7 over the Indian Ocean. The SST bias has a pattern of cold north and warm south from January to May, with the coldest bias over the Arabian Sea. A pattern of warm west and cold east develops after May and maintains until October. This new pattern starts to decay from November and restores to the January-May northsouth pattern in December. Therefore, the SST difference between the historical and AMIP run can largely explain the $\mathrm{CI}$ and the consequent rainfall biases over East Africa.

Figure 9 also shows the historical-AMIP surface wind difference. In general, the winds blow from the north to the south, owing to the large-scale thermal contrast of cool north and warm south and the consequent pressure gradient bias. The pattern of the surface wind biases implies that the Asian monsoon circulation is strengthened in winter but weakened in summer, suggesting that there might be a strong connection between the bias in East Africa and that in the large-scale Asian monsoon. The winds over the equatorial Indian Ocean are dominated by easterlies during the latter half year, which contributes to the maintenance of the warm SST bias over the western Indian Ocean (near the coast of East Africa).

To understand whether the SST annual cycle difference between the historical and AMIP run arises from surface heat flux or ocean dynamics, we need to calculate the heat budget of the mixed layer of the ocean. The 


\section{historical-AMIP CI in MRI-CGCM3}
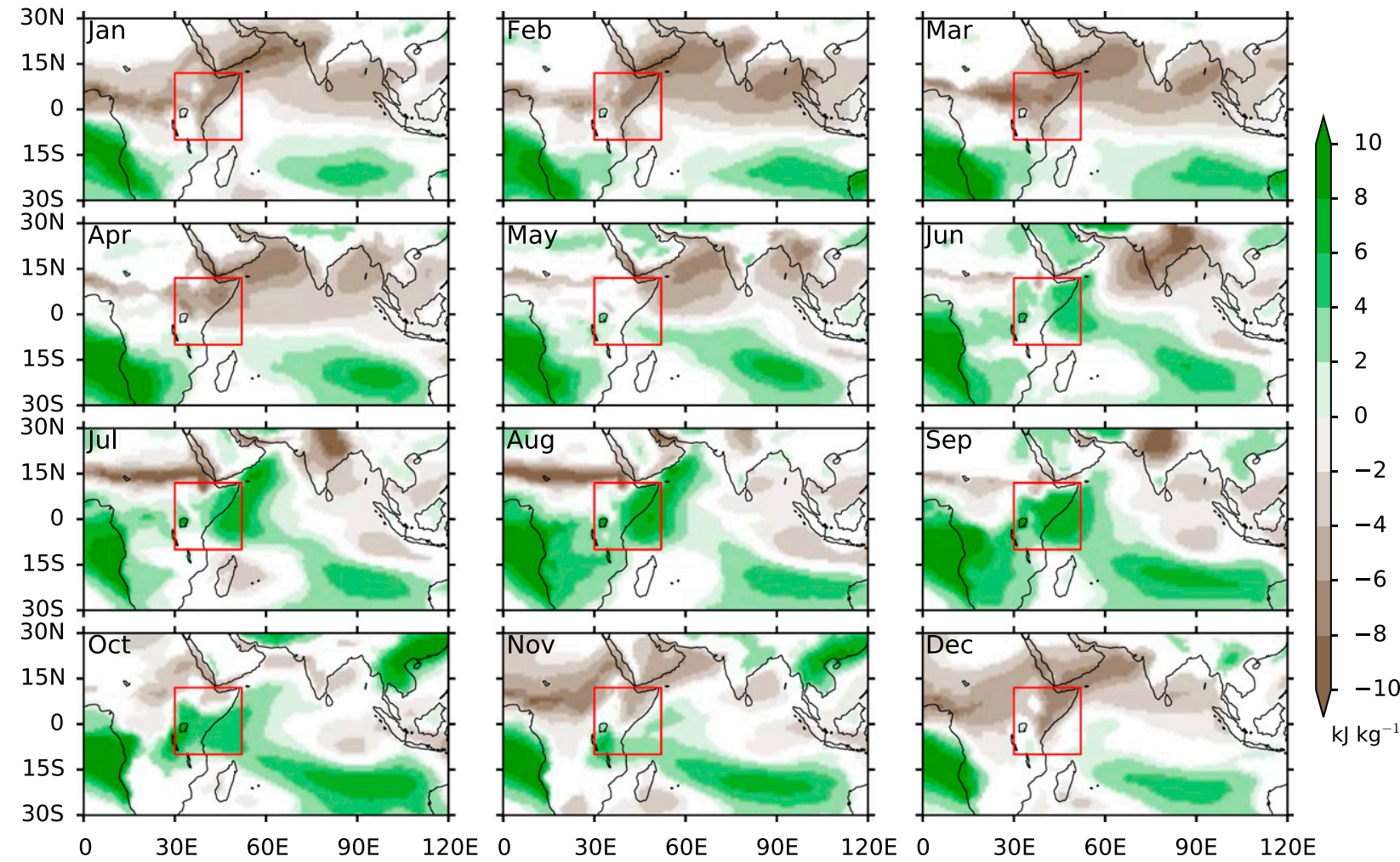

FIG. 6. As in Fig. 5 except for CI measured by near-surface moist static energy $\left(h_{s}\right)$ minus 700-hPa saturated moist static energy $\left(h_{700 \mathrm{hPa}}^{*}\right)$ - that is, $h_{s}-h_{700 \mathrm{hPa}}^{*}$. Only grids significant at the level 0.05 of the two-sided Student's $t$ test are shaded.

historical-AMIP form of the ocean mixed layer heat budget can be written as

$$
\rho c_{p} h \frac{\partial T^{\prime}}{\partial t}=R_{s}^{\prime}+R_{l}^{\prime}+\mathrm{LH}^{\prime}+\mathrm{SH}^{\prime}+D_{o}^{\prime}
$$

where primes denote the historical-AMIP differences; $\rho, c_{p}, h$, and $T$ are the seawater density, specific heat at constant pressure, mixed layer depth, and mixed layer average temperature, respectively; the left-hand side is the heat storage tendency and the right-hand side terms are the net shortwave radiation, net longwave radiation, latent flux, sensible heat flux (defined as positive into the ocean), and the three-dimensional advection and diffusion by ocean dynamics, respectively.

All the surface flux terms are archived for the CMIP5 models and thus can be estimated directly. The ocean dynamics term can be estimated as a residual in Eq. (1); that is,

$$
D_{o}^{\prime}=\rho c_{p} h \frac{\partial T^{\prime}}{\partial t}-\left(R_{s}^{\prime}+R_{l}^{\prime}+\mathrm{LH}^{\prime}+\mathrm{SH}^{\prime}\right)
$$

Figure 10 shows the heat budget annual cycle for MRI-CGCM3 averaged over the ocean grids within $10^{\circ} \mathrm{S}-10^{\circ} \mathrm{N}$ and $30^{\circ}-60^{\circ} \mathrm{E}$ as well as the corresponding historical-AMIP SST annual cycle difference. The mixed layer average temperature is approximated by SST when we estimate its tendency. Based on estimates of previous studies (Schneider 1996; de Boyer Montégut 2004), a constant 25-m-deep mixed layer is selected to estimate the heat storage change in the heat budget in this region. It can be seen from Fig. 10 that the sensible heat flux and the longwave radiation are much smaller in amplitude compared to other terms and the heat budget is balanced among heat storage tendency, latent heat flux, shortwave radiation, and ocean dynamics.

The SST annual cycle (red solid line) is characterized by warm biases during June-October and cold biases during the other months and dramatic transitions between the two phases. The latter is reflected by the historical-AMIP heat storage tendency $\left(\rho c_{p} h d T^{\prime} / d t\right)$ annual cycle (black solid line). During the cold-towarm transition from April to June, the heat storage tendency is dominated by insufficient upward latent flux and insufficient ocean dynamical cooling. The latent heat flux is larger in magnitude than the ocean dynamical term in April but smaller in June. In May, 
historical-AMIP $L_{v} q$ in MRI-CGCM3
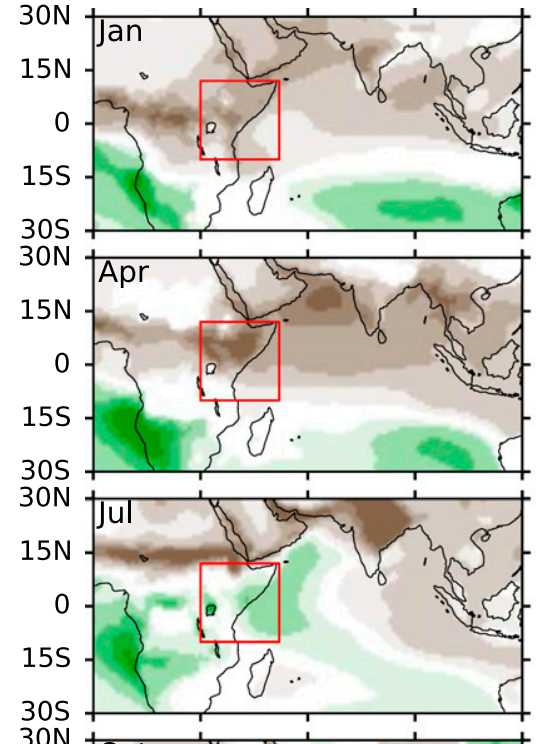

$30 \mathrm{~N}$

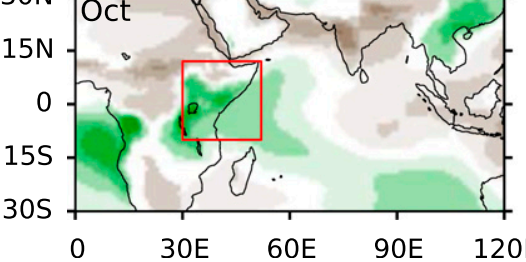

FIG. 7. As in Fig. 5 except for the moisture component of the near-surface moist static energy (i.e., $L_{v} q$ ). Only grids significant at the level 0.05 of the two-sided Student's $t$ test are shaded. the magnitudes of these two terms are comparable. The insufficient ocean dynamical cooling term maintains the warm SST bias until October when the SST bias decays close to zero. The second SST transition, from warm to cold, peaks in October and November and too little shortwave radiation ( $R_{s}^{\prime}$, blue solid line) dominates the negative heat storage tendency, probably owing to excess precipitation and clouds (Fig. 5). The dominant term eventually shifts to the excess latent heat flux $\left(\mathrm{LH}^{\prime}\right.$, green solid line) in January and February, perhaps arising from stronger Asian winter monsoon northeasterlies over the Indian Ocean. Therefore, insufficient ocean dynamical cooling and latent flux both are responsible for the development of the warm SST bias, while insufficient shortwave radiation and excess latent heat flux mainly contribute to the cold SST bias.

\section{Conclusions and discussion}

In this study, we investigate the coupled-modelinduced bias of the East African rainfall annual cycle common in CMIP3/5 that overestimates the short rains (OND) and underestimates the long rains (MAM) by comparing the historical (CMIP style) and the corresponding AMIP (AMIP style) runs for each model, with particular emphasis on the MRI-CGCM3. The framework of convective instability (CI) and moist static

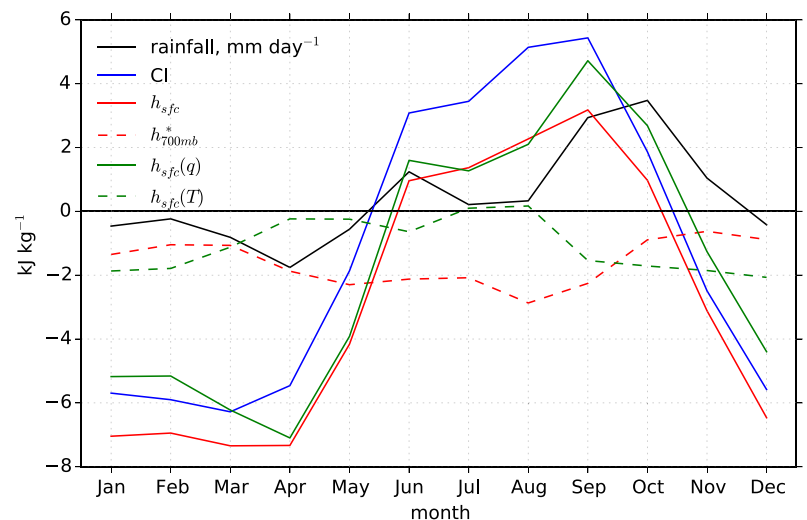

FIG. 8. Rainfall and CI (as well as its different components) of historical-AMIP for MRI-CGCM3 averaged over East Africa (the gray shaded grids shown in the mini panel of Fig. 1). The nearsurface moist static energy $h_{\text {src }}$ and and the 700-hPa saturated moist static energy $h_{700 \mathrm{mb}}^{*}$ are shown.. CI is measured as $h_{\mathrm{sfc}}-h_{700 \mathrm{mb}}^{*}$, and $h_{\text {sfc }}(q)$ and $h_{\text {src }}(T)$ are the components of $h_{\text {sfc }}$ associated with moisture and temperature, respectively. 


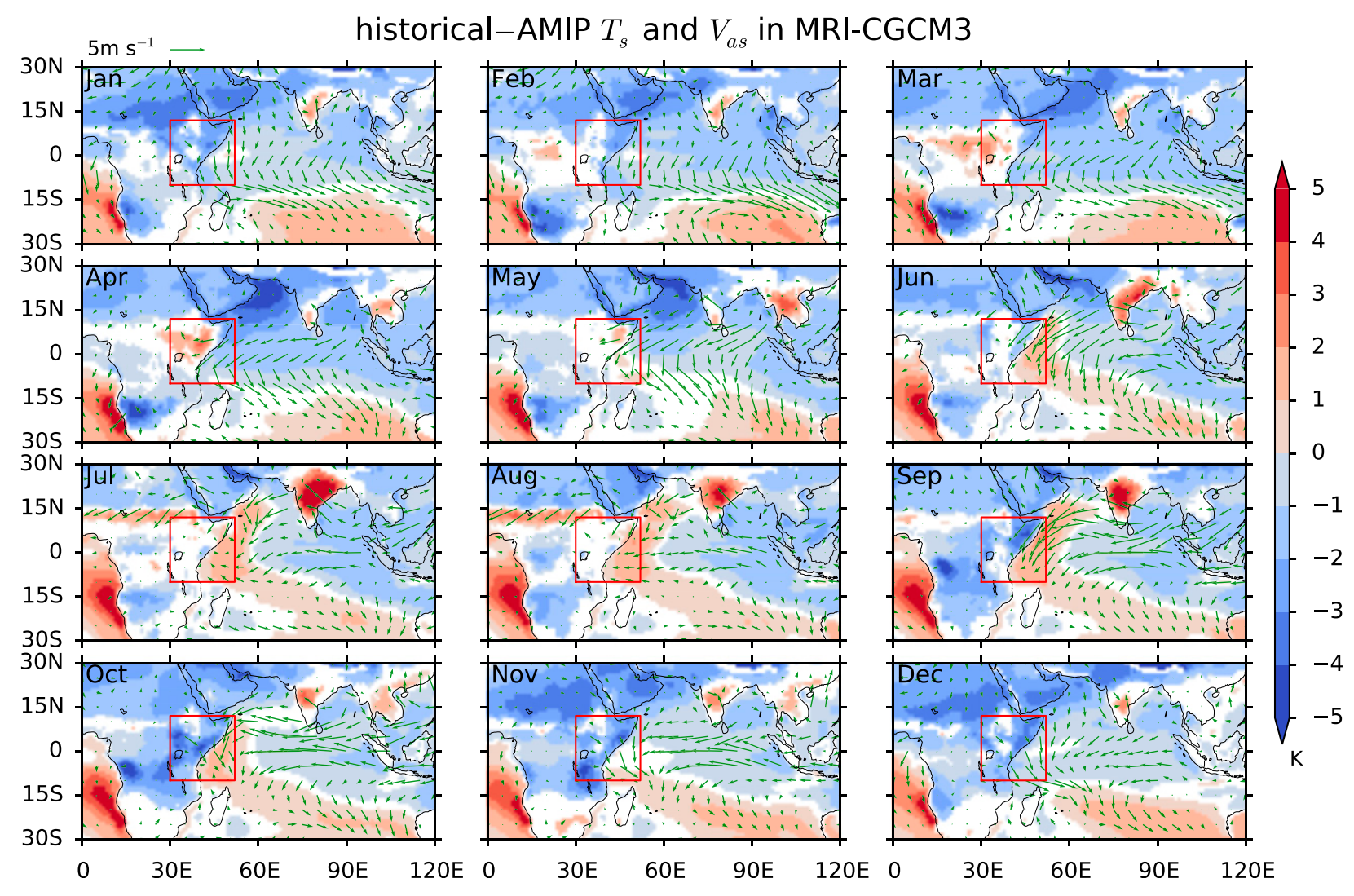

FIG. 9. As in Fig. 5 except for surface temperature $T_{s}$ (shading) and near-surface winds $\mathbf{V}_{\text {as }}$ (quivers). Only grids significant at the level 0.05 of the two-sided Student's $t$ test are shaded.

energy (MSE) link this bias to other tropical- or globalscale biases that have been found in previous studies (Cai and Cowan 2013; Wang et al. 2014). The following conclusions have been reached:

- East Africa is wetter in CMIP5 historical runs than AMIP runs during the OND short rains season but drier in the MAM long rains season.

- The AMIP run of MRI-CGCM3 reproduces the observed rainfall annual cycle over East Africa very well while its coupled historical run has a similar but stronger bias as the coupled multimodel mean. Therefore, MRI-CGCM3 serves as an exemplary model to study the coupled-model-induced rainfall bias over East Africa.

- The historical-AMIP monthly climatology rainfall bias can be explained by the bias in CI, which itself is dominated by the bias in near-surface MSE. The moisture component is the dominant term in the near-surface MSE while the temperature component is secondary.

- The near-surface MSE bias of historical-AMIP is modulated by SST bias over the western Indian Ocean.
- Insufficient ocean dynamical cooling and latent flux both are responsible for the development of the warm SST bias of historical-AMIP in MRI-CGCM3, while insufficient shortwave radiation and excess latent heat flux mainly contribute to the cold SST bias.

Wang et al. (2014) have shown that there is a globalscale cold Northern Hemisphere-warm Southern Hemisphere bias common to the CMIP5 coupled models, which they propose is linked to the Atlantic meridional overturning circulation being too weak. Consistently, in an observational and modeling study, Kang et al. (2015) found that the Atlantic overturning was indeed responsible for the Northern Hemisphere being warmer than the Southern Hemisphere. The cold north and warm south SST bias over the Indian Ocean dominant during December-May found in our study seems to be a local manifestation of this global-scale bias and can explain the drier long rains season over East Africa in coupled models. However, during JuneNovember, the north-south asymmetry over the Indian Ocean is replaced by a west-east contrast: warmer-thanobserved SSTs in the west and colder-than-observed 


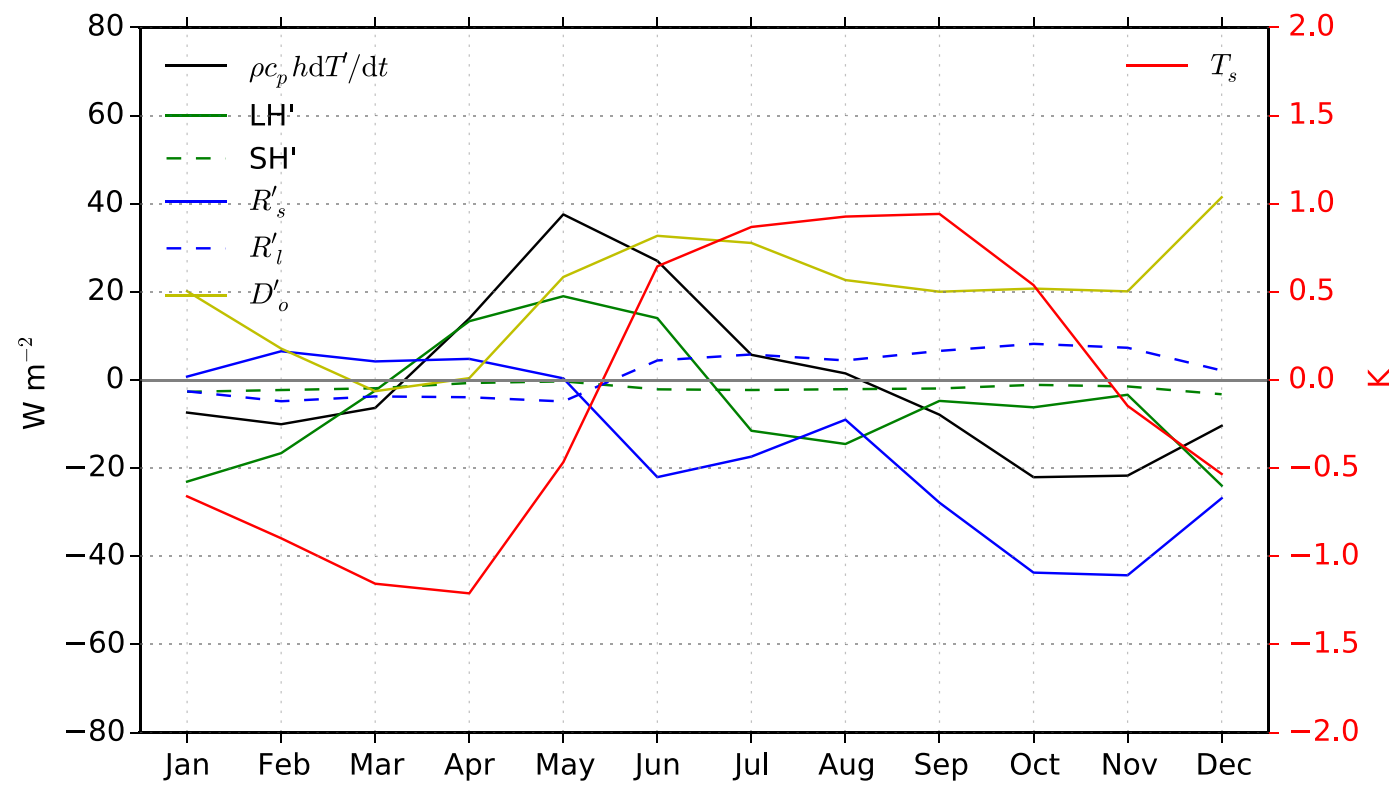

FIG. 10. Historical-AMIP SST and the ocean mixed layer heat budget in Eq. (1) in MRI-CGCM3, averaged over the ocean grids of $10^{\circ} \mathrm{S}-10^{\circ} \mathrm{N}, 30^{\circ}-60^{\circ} \mathrm{E}$.

SSTs in the east. These SST biases in the MRI-CGCM3 coupled model greatly increases rainfall over East Africa and can explain the wet bias during the short rains season. The mechanism behind the warm west and cold east asymmetry might be linked to the unrealistic mean thermocline slope tilting upward toward the eastern Indian Ocean as pointed out in Cai and Cowan (2013), who used it to explain the larger amplitude of the Indian Ocean dipole (IOD) in CMIP3/5 models. However, what ultimately causes the thermocline bias and the detailed processes that develop the bias are less clear and will be explored in the future.

We also notice that the coupling-induced biases of East African precipitation and the Indian Ocean SSTs in the model MRI-CGCM3 (Fig. 5 and Fig. 9) are accompanied by dry biases of the Indian summer monsoon. Recent studies have shown that SST biases over the Indian Ocean (Prodhomme et al. 2014), including the cold bias of the Arabian Sea (Levine et al. 2013), could contribute to the dry Indian summer monsoon in coupled models relative to observations or their corresponding SST-forced simulations. However, a dry Indian summer monsoon could impact Indian Ocean SSTs and East African precipitation via change of the surface winds over the Indian Ocean. Drier summer India implies a weak monsoon circulation, including the low-level winds in the Somali jet region. This could lead to reduced evaporation and weakened coastal upwelling over the western Indian Ocean off the coast of East Africa and warm the SST biases. This is consistent with the analysis of SST biases in the coupled models. However, this anomalous atmospheric forcing is most likely a feedback rather than the cause of the SST bias over the western Indian Ocean, as illustrated in the surface heat budget difference between the MRICGCM3 AMIP run and the ERA-Interim reanalysis in Fig. 11. The latent heat flux difference (green solid line) is negative year round over the western Indian Ocean and thus is continually cooling the SSTs there. Therefore, the cause of the western Indian Ocean SST bias is from the ocean component of the atmosphere-ocean coupled system.

The warm bias in the west and cold bias in the east over the Indian Ocean weakens the zonal asymmetry of the observed SST. This weakening is not unique to the Indian Ocean but can also be seen over the Pacific and Atlantic Oceans (Fig. 12a). The annual mean SST zonal asymmetry bias is weak over the Indian Ocean as a result of pronounced seasonality but very strong over the Pacific and Atlantic Oceans because of dramatic warming over the tropical eastern basins, especially near the western coasts of South America and Africa. The warm biases over the tropical eastern Pacific and Atlantic in coupled climate models have also been reported in previous studies and explained by excess heat flux into the ocean due to insufficient low-level clouds (Mechoso et al. 1995; Huang et al. 2007) and insufficient cooling by ocean dynamical processes (Colas et al. 2012). The general weakening of the zonal SST 


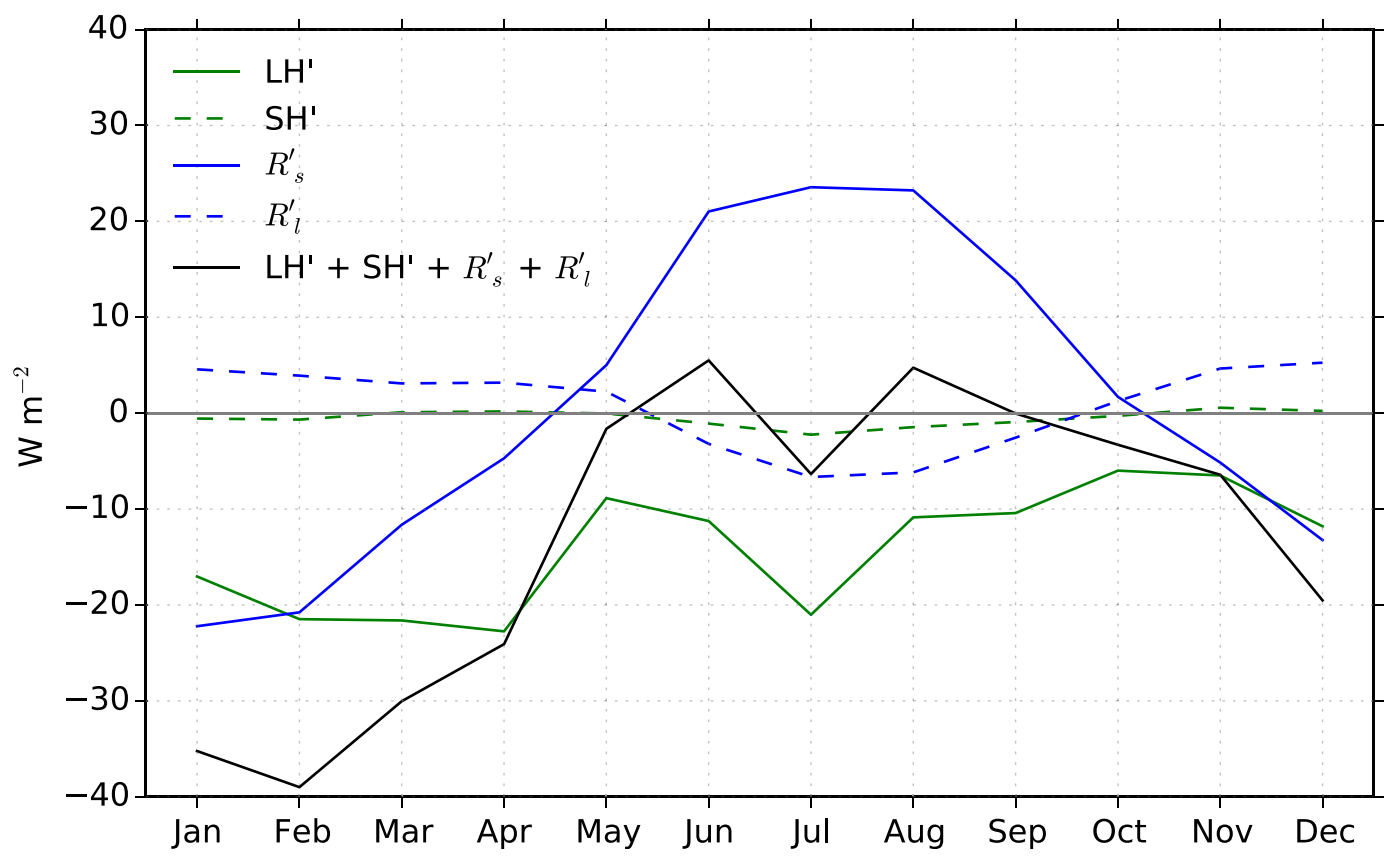

FIG. 11. Difference of the surface heat budget terms in Eq. (1) between the MRI-CGCM3 AMIP experiment and ERA-Interim, averaged over the ocean grids of $10^{\circ} \mathrm{S}-10^{\circ} \mathrm{N}, 30^{\circ}-60^{\circ} \mathrm{E}$.

asymmetry over all the tropical ocean basins in coupled climate models suggests that these coupled models might have difficulty in capturing the correct ocean processes that are important in determining the SSTs in equatorial and coastal upwelling regions. Consequently, these coupled models might underestimate the thermostat mechanism as proposed by Clement et al. (1996). Figure $12 \mathrm{~b}$ shows the change of multimodel mean

a) historical-AMIP

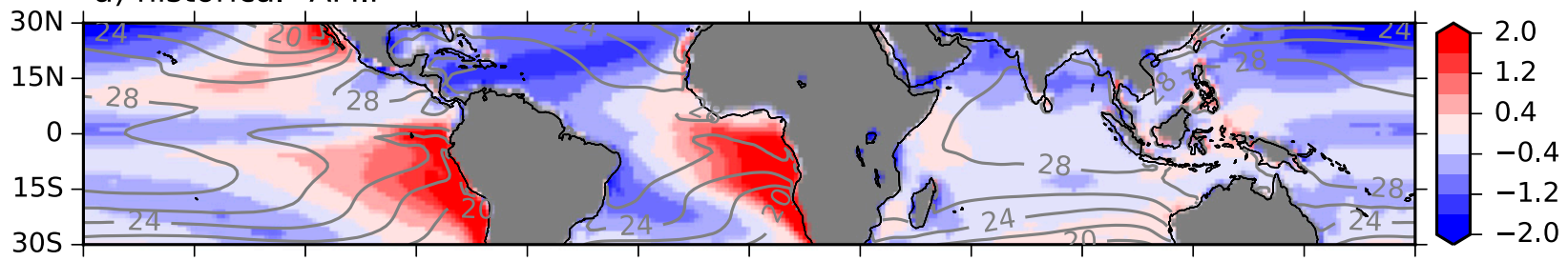

b) RCP8.5-historical (tropical mean removed)

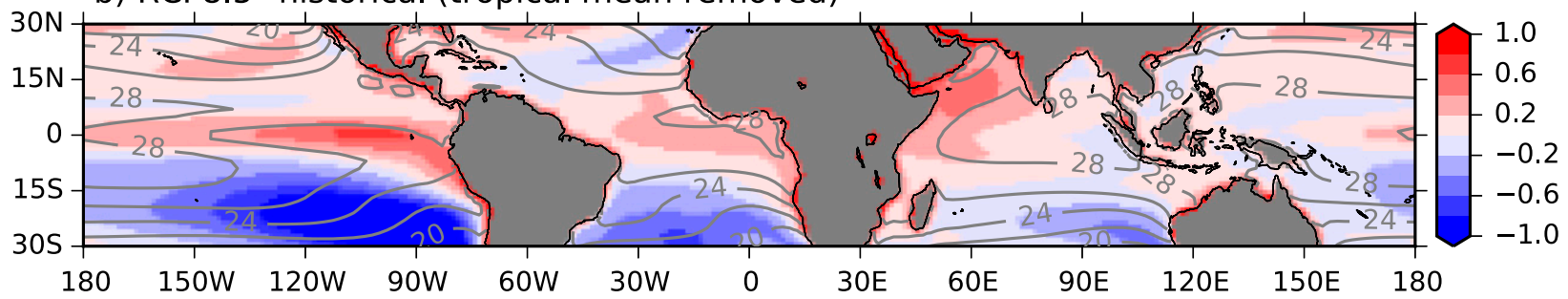

FIG. 12. (a) Annual mean SST climatology of the CMIP5 AMIP runs (contours) and its change from the AMIP to the multimodel mean of the historical runs (colors). (b) Multimodel mean annual mean SST climatology of the CMIP5 historical runs (contours) and its change from the historical to RCP8.5 runs (colors; the $30^{\circ} \mathrm{S}-30^{\circ} \mathrm{N}$ tropical mean change has been removed to emphasize the spatial pattern of the nonuniform component). The models used to calculate the multimodel mean are the 38 models from the CMIP5 that have surface temperature available in both the historical and RCP8.5 runs. (The descriptions of these models are from http://kage.ldeo.columbia.edu: 81/expert/SOURCES/.LDEO/.ClimateGroup/.PROJECTS/.IPCC/.CMIP5/.MultiModelMeans/.MMM-v2/.dataset_documentation. html.) The climatology is estimated based on the period of 1979-2005 for the AMIP and historical runs and 2070-99 for the RCP8.5 runs. The units are ${ }^{\circ} \mathrm{C}$. 
annual mean SST from the 1979-2005 historical runs to the 2070-99 RCP8.5 runs in CMIP5 (colors; the $30^{\circ} \mathrm{S}-30^{\circ} \mathrm{N}$ tropical mean has been removed to emphasize the nonuniform component). This also implies a weakening of the zonal SST asymmetry near the equator over all the ocean basins. The projection of much faster SST warming off the coast of East Africa than over the equatorial eastern Indian Ocean might partly explain the wetting projection in East Africa. However, if the response of SSTs to anthropogenic forcings in coupled models is biased by their bias in simulating current tropical zonal SST asymmetry, then the reliability of these SST projections and the associated precipitation projections are questionable.

Acknowledgments. This work was supported by NOAA Award NA10OAR4310137 (Global Decadal Hydroclimate Variability and Change). Funding for BL was provided by the National Science Foundation under Award AGS 12-52301. We thank Dr. Bill Boos and the two anonymous reviewers for their helpful suggestions and comments.

\section{REFERENCES}

Anyah, R. O., and W. Qiu, 2012: Characteristic 20th and 21st century precipitation and temperature patterns and changes over the Greater Horn of Africa. Int. J. Climatol., 32, 347-363, doi:10.1002/joc.2270.

Bollasina, M. A., and Y. Ming, 2013: The general circulation model precipitation bias over the southwestern equatorial Indian Ocean and its implications for simulating the South Asian monsoon. Climate Dyn., 40, 823-838, doi:10.1007/ s00382-012-1347-7.

Cai, W., and T. Cowan, 2013: Why is the amplitude of the Indian Ocean Dipole overly large in CMIP3 and CMIP5 climate models? Geophys. Res. Lett., 40, 1200-1205, doi:10.1002/ grl.50208.

Clement, A. C., R. Seager, M. A. Cane, and S. E. Zebiak, 1996: An ocean dynamical thermostat. J. Climate, 9, 2190-2196, doi:10.1175/1520-0442(1996)009<2190:AODT>2.0.CO;2.

Colas, F., J. C. McWilliams, X. Capet, and J. Kurian, 2012: Heat balance and eddies in the Peru-Chile current system. Climate Dyn., 39, 509-529, doi:10.1007/s00382-011-1170-6.

de Boyer Montégut, C., 2004: Mixed layer depth over the global ocean: An examination of profile data and a profile-based climatology. J. Geophys. Res., 109, C12003, doi:10.1029/ 2004JC002378.

Dee, D. P., and Coauthors, 2011: The ERA-Interim reanalysis: Configuration and performance of the data assimilation system. Quart. J. Roy. Meteor. Soc., 137, 553-597, doi:10.1002/ qj.828.

Funk, C., M. D. Dettinger, J. C. Michaelsen, J. P. Verdin, M. E. Brown, M. Barlow, and A. Hoell, 2008: Warming of the Indian Ocean threatens eastern and southern African food security but could be mitigated by agricultural development. Proc.
Natl. Acad. Sci. USA, 105, 11081-11086, doi:10.1073/ pnas.0708196105.

Harris, I., P. D. Jones, T. J. Osborn, and D. H. Lister, 2014: Updated high-resolution grids of monthly climatic observationsThe CRU TS3.10 dataset. Int. J. Climatol., 34, 623-642, doi:10.1002/joc.3711.

Huang, B., Z.-Z. Hu, and B. Jha, 2007: Evolution of model systematic errors in the Tropical Atlantic Basin from coupled climate hindcasts. Climate Dyn., 28, 661-682, doi:10.1007/ s00382-006-0223-8.

Huffman, G. J., and Coauthors, 2007: The TRMM Multisatellite Precipitation Analysis (TMPA): Quasi-global, multiyear, combined-sensor precipitation estimates at fine scales. J. Hydrometeor., 8, 38-55, doi:10.1175/JHM560.1.

, R. F. Adler, D. T. Bolvin, and G. Gu, 2009: Improving the global precipitation record: GPCP Version 2.1. Geophys. Res. Lett., 36, L17808, doi:10.1029/2009GL040000.

Kang, S. M., R. Seager, D. M. Frierson, and X. Liu, 2015: Croll revisited: Why is the northern hemisphere warmer than the southern hemisphere? Climate Dyn., 44, 1457-1472, doi:10.1007/s00382-014-2147-z.

Levine, R. C., A. G. Turner, D. Marathayil, and G. M. Martin, 2013: The role of northern Arabian Sea surface temperature biases in CMIP5 model simulations and future projections of Indian summer monsoon rainfall. Climate Dyn., 41, 155-172, doi:10.1007/s00382-012-1656-x.

Li, G., and S. P. Xie, 2014: Tropical biases in CMIP5 multimodel ensemble: The excessive equatorial Pacific cold tongue and double ITCZ problems. J. Climate, 27, 1765-1780, doi:10.1175/ JCLI-D-13-00337.1.

— S.-P. Xie, and Y. Du, 2015: Monsoon-induced biases of climate models over the tropical Indian Ocean. J. Climate, 28, 3058-3072, doi:10.1175/JCLI-D-14-00740.1.

Mechoso, C., and Coauthors, 1995: The seasonal cycle over the tropical Pacific in coupled ocean-atmosphere general circulation models. Mon. Wea. Rev., 123, 2825-2838, doi:10.1175/ 1520-0493(1995)123<2825:TSCOTT>2.0.CO;2.

Otieno, V. O., and R. O. Anyah, 2013a: CMIP5 simulated climate conditions of the Greater Horn of Africa (GHA). Part I: Contemporary climate. Climate Dyn., 41, 2081-2097, doi:10.1007/s00382-012-1549-z.

, and — 2013b: CMIP5 simulated climate conditions of the Greater Horn of Africa (GHA). Part II: Projected climate. Climate Dyn., 41, 2099-2113, doi:10.1007/ s00382-013-1694-z

Prodhomme, C., P. Terray, S. Masson, T. Izumo, T. Tozuka, and T. Yamagata, 2014: Impacts of Indian Ocean SST biases on the Indian Monsoon: As simulated in a global coupled model. Climate Dyn., 42, 271-290, doi:10.1007/ s00382-013-1671-6.

Rudolf, B., A. Becker, U. Schneider, A. Meyer-Christoffer, and M. Ziese, 2010: GPCC status report December 2010. GPCC Rep., 7 pp. [Available online at http://www.dwd.de/DE/ leistungen/wzn/publikationen/GPCC_status_report_2010. pdf?__blob $=$ publicationFile\&v $=2$.]

Schneider, E. K., 1996: A note on the annual cycle of sea surface temperature at the equator. COLA Rep. 36, 16 pp. [Available online at ftp://cola.gmu.edu/pub/ctr/ctr_36.pdf.]

Shongwe, M. E., G. J. van Oldenborgh, B. van den Hurk, and M. van Aalst, 2011: Projected changes in mean and extreme precipitation in Africa under global warming. Part II: East Africa. J. Climate, 24, 3718-3733, doi:10.1175/ 2010JCLI2883.1. 
Taylor, K. E., R. J. Stouffer, and G. A. Meehl, 2012: An overview of CMIP5 and the experiment design. Bull. Amer. Meteor. Soc., 93, 485-498, doi:10.1175/BAMS-D-11-00094.1.

Wang, C., L. Zhang, S.-K. Lee, L. Wu, and C. R. Mechoso, 2014: A global perspective on CMIP5 climate model biases. Nat. Climate Change, 4, 201-205, doi:10.1038/ nclimate2118.

Williams, A. P., and C. Funk, 2011: A westward extension of the warm pool leads to a westward extension of the Walker circulation, drying eastern Africa. Climate Dyn., 37, 2417-2435, doi:10.1007/s00382-010-0984-y.
Xie, P., and P. A. Arkin, 1997: Global precipitation: A 17-year monthly analysis based on gauge observations, satellite estimates, and numerical model outputs. Bull. Amer. Meteor. Soc., 78, 2539-2558, doi:10.1175/1520-0477(1997)078<2539: GPAYMA $>2.0 . \mathrm{CO} ; 2$.

Yang, W., R. Seager, M. A. Cane, and B. Lyon, 2014: The East African long rains in observations and models. J. Climate, 27, 7185-7202, doi:10.1175/JCLI-D-13-00447.1. , and - 2015: The annual cycle of East African precipitation. J. Climate, 28, 2385-2404, doi:10.1175/ JCLI-D-14-00484.1. 